considerations. Biomedical Research Involving Animals is a report of the proceedings of the 1983 conference which discussed a draft of the Guiding Principles for Research using Animals presented at the conference and which it was hoped would provide widely applicable criteria for establishing codes of practice or legislation concerning the use of laboratory animals for scientific purposes.

Whilst no one could fault the intention, the list of participants emphasises the rather one-sided nature of the proceedings. Of some 200 participants, scientists outnumbered animal welfarists by more than 20 to 1 . The sooner those involved in any of the scientific disciplines accept that responsible lay opinion in all areas where the welfare of man or animal is at stake must be given equal weight with scientific opinion, the better.

The attitude expressed by one scientist at the round table conference that those who are not in favour of experiments with animals simply do not understand what basic scientific method is about, is no longer true or acceptable.

Nevertheless, Biomedical Research Involving Animals is a useful selection of papers and discussions on this controversial and contentious issue. The conference was divided into three sessions, each of which included three or four papers followed by discussion: Scientific Progress and Research Involving Animals; Determinants of Future Policy Regarding Research Involving Animals, and Care and Protection of Laboratory Animals. The book ends with reports and summaries by the session chairmen.

I found the most interesting and useful paper was that of Dr Zimmermann, of the International Association for the Study of Pain, on Ethical Considerations in Relation to Pain in Animal Experimentation. In discussion, Dr Zimmermann makes the point which should give pause for thought to all those involved in experimental research:

\begin{abstract}
'As long as we do not know more about species-specific expressions for pain and suffering, it is perhaps useful to assume that the pain is not less than in humans. It might be more, maybe, I am not sure about that. For example, giving an injection to an animal is certainly much more painful for the animal than for a human because the animal cannot rationalise the injection'.
\end{abstract}

I was somewhat disappointed in the dis- cussion sections and believe these would have been more lively had there been greater animal-welfare participation.

One serious criticism is that to facilitate understanding of the discussion, the original draft of the International Guiding Principles is included as an annex but the final version of the Principles resulting from the round table conference is not included and is published separately.

Nevertheless, this is a useful study of the viewpoints about the use of animals in research and will be of interest to those on both sides of the fence.

CLIVE HOLLANDS Secretary,

Committee for the Reform of Animal Experimentation, (CRAE), Edinburgh

\section{Just Health Care}

Norman Daniels, 245 pages, London, $£ 22.50$ hard cover, $£ 7.95$ soft cover, Cambridge University Press, 1985.

This book addresses an intriguing question: What do we mean by justice in health care? It is 'an essay in medical ethics', although it concentrates on the social level of decision-making rather than the individual decisions which are more commonly the concern of medical ethics.

Daniels leads us through problems of the nature of health care per se and what is meant by 'need' to distributive theories and definitions of equal access. $\mathrm{He}$ considers equity by age group and equity to providers before moving away from the formal health-care system to discuss equity regarding health risks in the work place, concluding with his own musings on the relationship between philosophy and public policy.

The book deals with important issues. However, it is disappointing in that it does less than justice to the subject. It is worth reading, more as a stimulus to thought on the issues it raises rather than for any answers it provides.

Not that it is justified to expect answers to the very difficult question: what is just health care? However, a clearer, more insightful set of signposts to getting to the answer would have been welcome.

The most interesting part of the book deals not with health care per se but the regulation of hazards at work. What should the basis of such regulation be? Technological feasibility? Some costbenefit calculus? To what extent should individual freedoms to be exposed to hazards to health be respected? Should individuals be coerced into safety? Daniels suggests ( $p$ 159) that in general we ought to preserve individual autonomy but he adds the important rider: "If unregulated worker "choices" about risk-taking must fail, or generally do fail, to be informed, competent or truly voluntary, then we are not compromising autonomy by intervening'. But the world is not so neatly divided. And in the middle ground of partially informed, not wholly incompetent and at times voluntary risk-taking what do we do? Perhaps the answer is simply to agree the desirability for intervention on the basis of whether individuals at risk want such intervention. Messy perhaps; but also perhaps just. Maybe too it is equity in information that holds the key to justice in risk-taking and health care more generally.

Elsewhere and particularly on formal health-care justice, the book is slow to take off. This seems largely because of a failure to answer satisfactorily what is surely the key question 'Is health care special?' Daniels addresses it and concludes ( $p$ 57) that health care is special because ' 1 ) meeting health-care needs helps us maintain normal species functioning and that 2) normal functioning in turn has a major impact on an individual's share of the normal opportunity range for his society'.

Such a conclusion is less than satisfactory and it is a pity he did not devote more time to the ideas that as individuals we care about the health of others (and therefore about justice in health care) or that we want to do our fair share for the health of society more generally and as a result want everyone to have reasonable access to health care. Sorting out if and why health care is special is no easy task but Daniels needed somehow to address these questions better if the central thrust of the book was to sustain its momentum.

His discussion of the concept of need is not as helpful as it might be - again unfortunate, as it is difficult to discuss justice in health care without an adequate definition or at least view of what constitutes health care needs.

Equity for providers - especially doctors - is however raised in an interesting way, perhaps because it is less well documented than justice for consumers. His conclusion here is stronger than elsewhere: 'The restrictions on autonomy in treatment decisions imposed by just resource allocation policies ... violate no basic liberty of physicians or rights of patients'.

That comment is perhaps best read alongside his conclusion to the book that justice will vary depending on the 
framework or organisation and cultural setting in which it is discussed. Just health care, whatever it is, is likely to be different in different countries.

Fust Health Care raises important issues, issues which merit more debate. Insofar as the book fosters such debate it is worth a read.

PROFESSOR GAVIN MOONEY Director, Health Economic Research Unit, University of Aberdeen, Department of Community Medicine, Foresterhill, Aberdeen

\section{The Place of the Humanities in Medicine}

Eric J Cassell, 56 pages, New York, \$7.00, Hastings Center, 1984

This essay reviews the place that the humanities have held in medicine in the past and examines what they have to offer to modern medical practice. It looks at the changes in attitude that are occurring in health care and considers ways that philosophy, history and literature can help our understanding and facilitate these changes.

The historic review is short and rather superficial. It concludes that the growth in emphasis on scientific training and method following the publication in 1910 of the Flexner Report on Medical Education led to the undervaluing of a liberal education as a foundation for a medical career. This attitude has persisted until the present.

However, there are some indications of a recent change in emphasis. The amount of teaching of various courses including ethics, literature, philosophy, human values, religion and medical history - in some American medical courses is discussed, and it is concluded that there is a growing awareness of the need for doctors to be versed in the scope and value of the humanities, and for an increase in curricular time devoted to these subjects.

What the humanities have to offer, and how best they can be communicated to medical students takes up the bulk of this short monograph, and this section concludes that medicine cannot progress unless the humanities are given a full role in medical education and practice. The obstacles to achieving a balanced education, and possible solutions, are put forward in the conclusion to this book.

The range of the humanities covered in this short work means that arguments cannot be developed in depth. Neither are different benefits emphasised for different liberal studies. While some useful arguments are put forward, it is unlikely that this book will persuade those now unconvinced, that medical schools should introduce liberal studies courses.

\section{St George's Hospital Medical School London SW17}

\section{Nursing Models: Analysis and Evaluation}

Janice A Thibodeau, 157 pages, Belmont, California, \$10.95,

Wadsworth Inc, 1983

It is difficult to discuss this book without naming at least some of its chapter headings. They are: The development of nursing science; The relationship of theory to model development; Historical development of models of nursing practice; Types of conceptual model; Criteria for analysis and evaluation of a nursing model; each of the following four chapters is used for the analysis of one of the models; the penultimate chapter deals with the implications of models of practice for nurse managers and the book concludes with a chapter on the future directions of nursing.

Appropriately and courageously, the author attempts to define important concepts such as theory, model, paradigm, which are so liable to misuse and lack of understanding. Understandably, but regrettably, she does not achieve the clarity hoped for and her own use of the terms in the text tends to be somewhat blurred.

A nursing paradigm is described as one which contains four essential components, namely people, health, environment and nursing; however, in her analysis of the four models using her four-pronged structural framework, the 'nursing' component could just as easily be applicable to other disciplines such as physiotherapy. Thus, the fundamental problem of this book lies in the definitions of the components of a nursing paradigm on which the analysis and evaluation is based; they are circular, tautological and self-defeating.

The book has many assets. The author has responded to the urgent need for a critical review of nursing models and their possible application. She has provided a helpful perspective especially in the historical chapters. She has attempted to apply her framework to some of the best known nursing models. The bibliographical references are excellent and should prove valuable starting points for further reading. This is a useful book for libraries as a source book for students of nursing theories and models. It is not easy reading for nurse practitioners and, in my view, it does little to bridge the gap between the doers and thinkers, the author's wish expressed in the first paragraph of chapter one. The most fundamental criticism so far as readers of this journal are concerned is the notable lack of analysis of the many ethical issues intrinsic to any 'nursing model'.

LISBETH HOCKEY Freelance consultant, writer and Guest Professor, University of Uppsala, Sweden

\section{Ethics and Mental Retardation}

Authors/Editors L Kopelman and J C Moskop, xvi +258 pages, Dordrecht, $\$ 29.50$, Dfl 11.90, D Reidel Publishing Company, 1984

I approached the reading of this book with some trepidation for two reasons. There is so little written on ethical issues in relation to mental handicap that I very much wanted this book to fill a large gap in my knowledge and in the literature. Secondly, I feared that the book would be so full of legal and ethical jargon that it would be turgid, uninteresting and hard to understand for the average British reader. I am glad that I was proved wrong on both counts. This book covers a wealth of subjects within the topic from the issue of rights and responsibilities, respect and the effect of labelling, the interface between religion and disability, the law and public policy. Despite this being a book from the USA (and all the contributors come from that country) much of what is written is relevant to what happens, or should be happening in Great Britain.

The book is a collection of writings taken from the papers presented at a symposium held in 1981 in North Carolina, supported by both the School of Medicine and the Department of Philosophy at East Carolina University. The title of the symposium was Natural Abilities and Perceived Worth: Rights, Values and Retarded Persons. While multi-author books and in particular books that follow a symposium run the risk of repeating information already known and reproducing articles that vary unacceptably in complexity, this book manages to avoid both. However, section 1, on Examining the Rights Tradition, written entirely by philosophers, is probably the most difficult for doctors.

Perhaps the section that interested me most was section 3 , which explored the link between theology and disabil- 